\title{
EXPERIMENTAL RIGHT VENTRICLE TO PULMONARY ARTERY DISCONTINUITY: OUTCOME OF POLYURETHANE VALVED CONDUITS
}

\author{
Jacques Robin, MD $^{\mathrm{a}}$ \\ Stéphane Martinot, MVD ${ }^{\mathrm{b}}$ \\ Alain Curtil, MD \\ Catherine Vedrinne, $\mathrm{MD}^{\mathrm{a}}$ \\ François Tronc, $\mathrm{MD}^{\mathrm{a}}$ \\ Michel Franck, MVD ${ }^{\mathrm{b}}$ \\ Gérard Champsaur, MD
}

\begin{abstract}
Objective: The ideal substitute for the treatment of ventricle-pulmonary artery discontinuity remains a topic of controversy, because of calcifications and degeneration of biologic substitutes leading to subsequent reoperations. Because polyurethane valves used in ventricular assist devices show a satisfactory biocompatibility, the aim of this study was to evaluate a valved conduit composed of a Dacron graft incorporating a trileaflet $25 \mathrm{~mm}$ polyurethane valve. Methods: The conduit was implanted between the right ventricle and the main pulmonary artery in adult sheep, with ligation of the proximal pulmonary artery. The animals received no medications. Serial hemodynamic data were collected at the time of implantation and at postoperative intervals of 6 and 12 months. Results: The peak pressure gradient across the valve increased significantly between implantation $(0.17 \pm 5.6 \mathrm{~mm} \mathrm{Hg})$ and 6 months after operation $(7.3 \pm 3$ $\mathrm{mm} \mathrm{Hg}, p=0.0007)$ and remained stable thereafter $(6.7 \pm 3 \mathrm{~mm} \mathrm{Hg}$ at 12 months), whereas the cardiac output remained unchanged $(4.6 \pm 0.6 \mathrm{~L} / \mathrm{min}$ at implantation, $4 \pm 0.6 \mathrm{~L} / \mathrm{min}$ at 6 months, and $3.9 \pm 1.1 \mathrm{~L} / \mathrm{min}$ at 12 months). At the completion of the study, valve samples were processed and vapor coated with carbon for microscopic examination. There was one instance of nonadherent thrombus formation inside a cusp but no structural failures. The other valves were free of calcium deposits and no significant amounts of phosphorus could be detected by scanning electron microscopy and energy dispersive spectrometry. Conclusions: These data demonstrate the good hemodynamic performance, low thrombogenicity, and acceptable durability of the polyurethane valves implanted in the right side of the heart in a chronic sheep model. (J Thorac Cardiovasc Surg 1998; 115:898-903)
\end{abstract}

$\mathrm{R}$ ight ventricle-pulmonary artery (RV-PA) anatomic discontinuity is present in approximately $5 \%$ of hearts with congenital defects. ${ }^{1}$ In such cases, the surgical treatment may require the use of an RV-PA conduit. Different substitutes have been proposed including fresh aortic homografts, ${ }^{2}$ Dacron valved conduits containing bioprostheses $^{3-6}$ or mechanical valves, ${ }^{7}$ and more

From Claude Bernard University and Hôpital Cardiologique ${ }^{\mathrm{a}}$ and National Veterinary School, ${ }^{\mathrm{b}}$ Lyon, France.

Supported in part by a grant from the Antonin Poncet surgical research prize, Claude Bernard University, Lyon, France.

Received for publication June 19, 1997; revisions requested Sept. 23, 1997; revisions received Oct. 16, 1997; accepted for publication Oct. 16, 1997.

Address for reprints: J. Robin, MD, Hôpital Cardiologique, 59 Boulevard Pinel, 69003 Lyon, France.

Copyright (c) 1998 by Mosby, Inc.

$0022-5223 / 98 \$ 5.00+0 \quad \mathbf{1 2} / \mathbf{1} / \mathbf{8 7 0 5 1}$ recently cryopreserved aortic or pulmonary homografts. ${ }^{8-11}$ Whichever kind of substitute is used, many studies report valvular calcifications or degeneration associated with pseudointimal proliferation and progressive obstruction of the conduit, , 8, 9, 11, 12 imposing later reoperations with a rate ranging from $14 \%$ to $30 \%$ at 5 years and $32 \%$ to $100 \%$ at 10 years. $^{4,5,10-13}$

During the past decade we have observed an excellent immediate biocompatibility of the polyurethane valves used in temporary ventricular assist devices. ${ }^{14}$ Although the follow-up in this specific group of patients is rather short, low rates of thromboembolic complications and no valvular failures or calcifications have been reported. Such valves have been implanted experimentally with satisfactory results in long-term left ventricular assist devices between the apex of the left ventricle and the aorta. ${ }^{15}$ Furthermore, this valvular substi- 


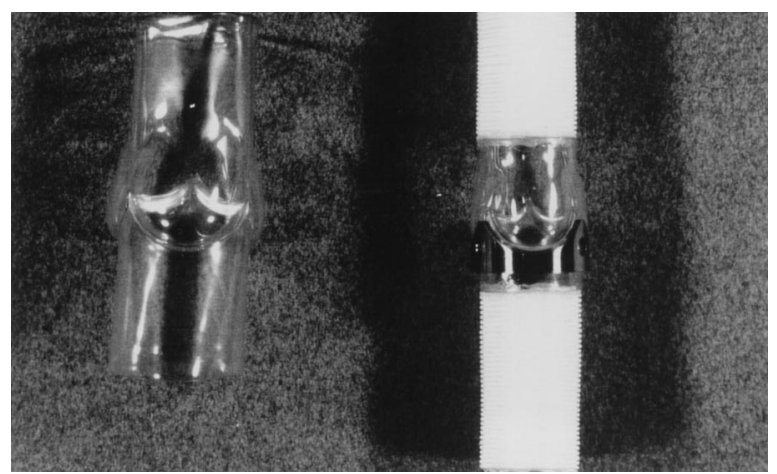

Fig. 1. Polyurethane valved conduit heat sealed to the Dacron graft.

tute will be used in one of the next generation of total implantable artificial hearts. ${ }^{16}$

However, the midterm outcome of such artificial valves has not been documented in the right side of the heart exposed to both low pressures and oxygen saturation levels. The aim of this experimental study was to evaluate the midterm hemodynamic performance, calcification occurrence, and durability of a new type of polyurethane valved conduit implanted as the only route between the RV and the PA in the fully mature sheep model for a 1-year period.

\section{Methods}

Conduit prototype (Fig. 1). The conduit consists of a trileaflet polyurethane valve (Abiomed Inc., Danvers, Mass.) assembled with a low-porosity Dacron graft, 25 $\mathrm{mm}$ in diameter (no. 244422, Boston Scientific Corp., Natick, Mass.). The three cusps are heat sealed within a polyurethane housing. An outside stent maintains some rigidity and avoids external compression of the soft polyurethane chamber. Each extremity is heat sealed to the Dacron conduit. The transvalvular gradient was tested in vitro at the time of manufacture, and for the set of valves implanted the mean value was $8 \pm 1.2 \mathrm{~mm} \mathrm{Hg}$ for a mean flow rate of $8 \mathrm{~L} / \mathrm{min}$ (peak flow $18 \mathrm{~L} / \mathrm{min}$ ).

Experimental protocol. The conduit was implanted in 6 adult sheep (weight $50 \pm 3.6 \mathrm{~kg}$ ). All animals received humane care in compliance with the guide of the National Veterinary School for laboratory animal studies. Animals were anesthetized via a jugular intravenous injection of ketamine $(5 \mathrm{mg} / \mathrm{kg})$ and diazepam $(0.25 \mathrm{mg} / \mathrm{kg})$ as a bolus. The sheep were endotracheally intubated and then supported by a volume-cycled respirator (MMS 107 ventilator MMS, 77500, Chelles, France) with a 10 cycle/min respiratory rate and a $15 \mathrm{ml} / \mathrm{kg}^{-}$tidal volume, so as to keep the arterial oxygen saturation value at $99 \%$. Anesthesia was maintained with a mixture of $1 \%$ to $1.5 \%$ inspired halothane and $20 \%$ nitrous oxide.

Animals were monitored with three-lead electrocardiography. The left carotid artery was used for systemic arterial blood pressure monitoring and for blood gas

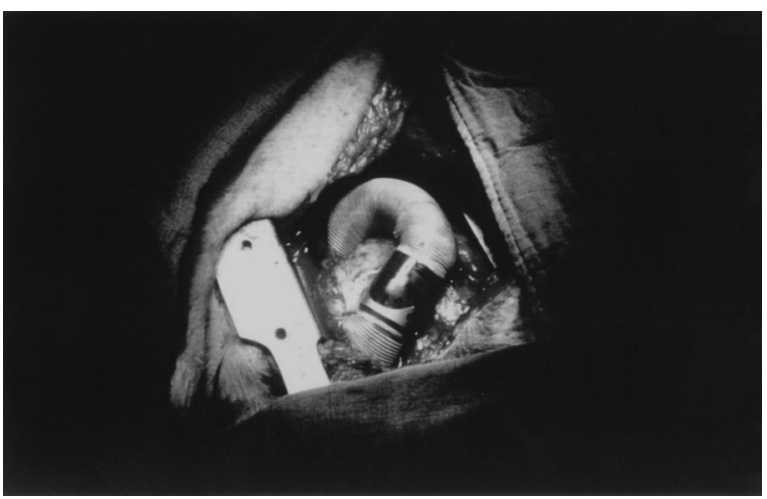

Fig. 2. Operative view of the RV-PA conduit implanted into position.

sampling (Radiometer ABL 330 gas analyzer, Copenhagen, Denmark). A 5F PA catheter (Baxter Catheter, Edwards Critical Care Division, Irvine, Calif.) was introduced percutaneously into the right jugular vein for complete catheterization of the right side of the heart and fluid infusion. Pressures were continuously recorded on a multichannel recorder (type 506 A, Kone Corporation Instrument Division, Espoo, Finland) with the use of pressure transducers (PVB transducer, SIMS Smiths Industries, Kirchseeon, Germany).

Technique of implantation. Under sterile conditions, a left anterior thoracotomy was performed in the fourth intercostal space. The pericardium was opened anterior to the phrenic nerve and the heart suspended. The anterior aspect of the RV was exposed along with the main PA, which was dissected out and controlled with a tape for later ligation. The operation was performed without bypass and with the use of general anticoagulation (heparin $1 \mathrm{mg} / \mathrm{kg}$ ) to limit the risk of thrombosis during RV and PA clamping. The RV anterior wall was clamped laterally after injection of a bolus of intravenous lidocaine (100 $\mathrm{mg}$ ) to avoid ventricular rhythm disturbances during the RV mobilization. An adequate ventriculotomy was performed on the clamped portion. The proximal anastomosis between the RV and the Dacron graft was done with a running suture of monofilament 4-0 polypropylene. The end-to-side distal anastomosis was then performed between the beveled Dacron graft and the main PA laterally clamped with use of the same suture technique. The conduit was carefully deaired before the completion of the anastomosis. Finally, the main PA was ligated proximal to this anastomosis. The conduit length and positioning were given paramount attention to avoid any kinking or compression of the conduit or the heart itself by the thoracic wall (Fig. 2). The operation was completed with chest closure over a chest tube left in place for 4 hours after extubation of the animal. An antibiotic was prescribed for 5 days. No cardiac medications were given and particularly no anticoagulation therapy. The animals were left fully ambulatory for the remainder of the study.

Data acquisition. Hemodynamic data were collected at the time of operation (T0) and at 6 (T1) and 12 (T2) months after operation. These data consisted of complete 
Table I. Hemodynamic data at each data collection point

\begin{tabular}{lccc}
\hline \multicolumn{1}{c}{ Hemodynamic parameter } & $T 0$ & $T 1$ & $T 2$ \\
\hline RV systolic pressure (mm Hg) & $26.00 \pm 5.66$ & $27.00 \pm 6.00$ & $32.33 \pm 7.53$ \\
RV end-diastolic pressure (mm Hg) & $11.67 \pm 6.22$ & $11.33 \pm 3.67$ & $3.50 \pm 1.81^{*}$ \\
PA systolic pressure (mm Hg) & $26.17 \pm 5.12$ & $19.67 \pm 6.74$ & $25.83 \pm 8.45$ \\
PA mean pressure (mm Hg) & $18.17 \pm 5.60$ & $13.00 \pm 5.02$ & $17.83 \pm 4.45$ \\
PA diastolic pressure (mm Hg) & $12.67 \pm 7.20$ & $8.33 \pm 3.27$ & $10.83 \pm 4.58$ \\
PA occluded pressure (mm Hg) & $13.00 \pm 6.13$ & $12.00 \pm 4.55$ & $14.50 \pm 6.53$ \\
RV-PA systolic gradient & $0.17 \pm 5.60$ & $7.33 \pm 3.01 \dagger$ & $6.70 \pm 3.00 \dagger$ \\
Cardiac output (L/min) & $4.60 \pm 0.60$ & $4.00 \pm 0.60$ & $3.90 \pm 1.10$ \\
\hline
\end{tabular}

${ }^{*} p=0.001$ between $\mathrm{T} 0$ and $\mathrm{T} 2$ and $p=0.01$ between $\mathrm{T} 1$ and $\mathrm{T} 2$ (analysis of variance).

$\dagger p=0.007$ between $\mathrm{T} 0$ and $\mathrm{T} 1$ and $p=0.04$ between $\mathrm{T} 0$ and $\mathrm{T} 2$.

pressure values in the right side of the heart including RV systolic pressure, RV end-diastolic pressure; systolic, diastolic, and mean PA pressure; PA occluded pressure; and pressure gradient along the right side of the heart. Cardiac output was also measured. All pressure measurements were obtained under conditions similar to the preimplantation conditions, that is, with the animals placed under general anesthesia and with use of a Swan-Ganz catheter (Baxter) introduced into the right jugular vein.

Pathologic examination was performed at the end of the study after the sheep were electively killed. The heart-lung blocks and prosthetic materials were removed. A macroscopic study was initially done to search for calcifications, thrombosis, and pseudointimal proliferation. A microscopic study was secondarily performed. The valves were stored in formaldehyde baths. They were rinsed with ethanol and cut on a band saw into several pieces. Segments of leaflets from each valve that included a valve edge and a piece of the commissures were rinsed again in ethanol after cutting, then dried at $40^{\circ} \mathrm{C}$ in air. The samples were vapor coated with carbon and examined by scanning electron microscopy (SEM) and energy dispersive spectrometry (EDS) methods (Analytical Answers, Woburn, Mass.). Only the proximal or inflow side of each valve was examined by microscopy because this is the most likely site for calcifications to occur.

Statistical analysis. Results were expressed as mean plus or minus the standard deviation. The Wilcoxon $t$ test and repeated-measures analysis of variance were used to compare changes in hemodynamic parameters at each time.

\section{Results}

The animals had a "normal life" after operation without clinical manifestations of infection, emboli, or other conduit-related complications.

Analysis of the hemodynamic data collected at the three different times (Table I) revealed only two variables with statistically significant changes. The $\mathrm{RV}$ end-diastolic pressure remained stable between $\mathrm{T} 0$ and $\mathrm{T} 1$, but decreased significantly between $\mathrm{T} 1$ and T2. A significant increase in the pressure gradient at the valve level appeared between $\mathrm{T} 0$ and $\mathrm{T} 1$, and the pressure remained stable thereafter. Given the length of the conduit, the pull-back pressure curve could easily rule out pressure gradients at either the proximal or distal anastomosis. Unlike the pressure gradient, the cardiac output remained stable over time (Table I).

At macroscopic study, there was no significant ventricular hypertrophy. There were no instances of pulmonary emboli or infectious endocarditis found by thorough macroscopic dissection of the pulmonary vascular bed at autopsy. A pseudointimal proliferation was usually observed inside the Dacron grafts, but the polyurethane chambers seemed free of macroscopic deposits. The valves appeared visually to be smooth surfaced. No structural valve deterioration (fracture, leaflet tear, or macroscopic calcification) was observed. There was one instance of valve thrombosis partially molding the distal side of one cusp and not strongly adherent to the valve surface. The details of each explant analysis are as follows.

Valve 1. This was the valve partially blocked by tissue deposits. SEM of the polymer surface of the valve leaflet showed very thin, patchy deposits, some of which contained calcium (the others were mainly sodium chloride). The calcium deposits were predominantly found along the edge of the leaflets. The morphologic features of the calcium-containing deposits were not similar to those on the other valves; these deposits were flatter and less crystalline in appearance. Overall, the leaflet surface was relatively clean but there were some adhering proteins near the commissure and scattered salt $(\mathrm{NaCl})$ crystals all over the leaflet.

Valve 2. This valve was mostly clear. SEM showed some small calcium-containing deposits about 10 to $20 \mu \mathrm{m}$ in size, which were more prevalent near the tip of the leaflet than near the base. The largest deposits were about $100 \mu \mathrm{m}$ in size.

Valve 3. SEM showed a very clean surface with small scattered nodules of a few microns in diameter, which EDS determined to be of a very high 
calcium content. Image analysis estimated surface coverage by the nodules of $3 \%$ to $4 \%$.

Valve 4. This valve was very clear and clean with no visible deposits. SEM showed a fairly uniform distribution of very small calcium nodules, less than $1 \mu \mathrm{m}$ in diameter (Fig. 3). There were more nodules per unit area than in valve 3 , but they were much smaller. EDS confirmed the high calcium content of the nodules (Fig. 4). Surface coverage determined by image analysis was $6 \%$ to $9 \%$.

Valve 5. SEM showed a mostly clear surface with a fairly even distribution of very small nodules (1 $\mu \mathrm{m})$. The EDS spectrum of the nodule showed a very high calcium content. Surface coverage by nodules was $3 \%$ to $5 \%$ as determined by image analysis.

Valve 6. This valve had very dark coloration on the leaflets. SEM showed very light, minor deposits. One feature near the base of the leaflet was a small piece of material, 10 to $100 \mu \mathrm{m}$ in size, approximately, which had been partially encapsulated in calcium-containing deposits. This feature was unique and not a uniform feature of the surface.

Globally, the valves were relatively free of deposits and particularly free of calcified deposits. The only apparently remarkable finding in the analysis was the almost complete absence of phosphorus when calcium was present. The calcium-containing deposits were not hydroxyapatite, but another form of calcium compound with a very high net calcium content. No deposits containing significant amounts of phosphorus could be found on any of the valves.

\section{Discussion}

To the best of our knowledge, chronic (1 year) animal implantation of polyurethane valves has never been reported in the right side of the heart exposed to low pressures and oxygen saturation levels. Such an experimental study addresses three issues, namely prototype specifications, calcification of the material, and midterm hemodynamic performance of the device.

Prototype specifications. The softness of the polyurethane housing presents a potential risk of compression or kinking, which was not observed in this study, because the metal stent maintains some rigidity. However, there still remains some risk of pseudointimal proliferation or calcification within the Dacron fabric part of the conduit, but this should be minimized in reducing the Dacron fabric length and the blood-contacting surface exposed to this material. Heat sealing between polyurethane

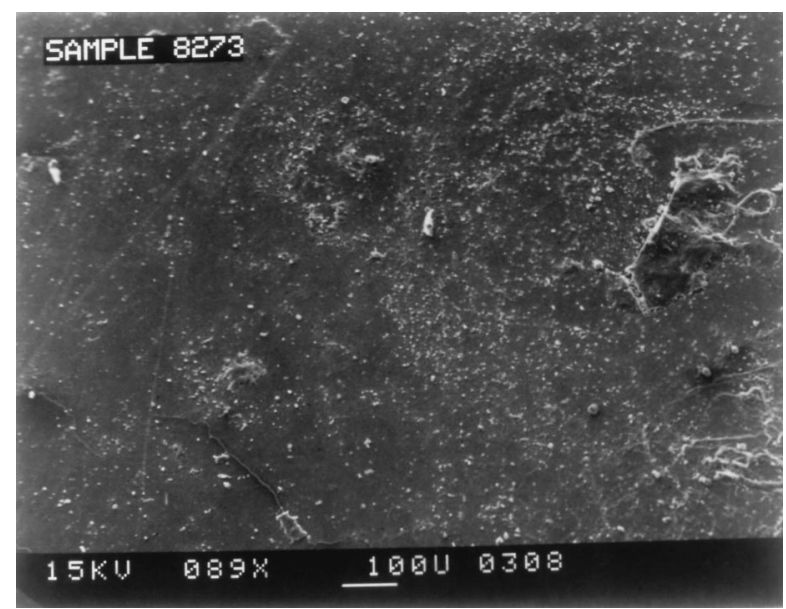

Fig. 3. Photomicrograph of a valve explanted at 1 year, showing a mostly clear surface with a fairly even distribution of $1 \mu \mathrm{m}$ size nodules.

and other material such as polytetrafluoroethylene would represent an alternative to prevent pseudointimal proliferation, at the expense of a more demanding manufacturing process. Moreover, no fibrous deposits were observed on the polyurethane component of the conduit. Thus it would be interesting to coat the inner part of the Dacron tube with polyurethane and to evaluate the long-term outcome of such material. Furthermore, the conduit was implanted in fully grown sheep and its diameter $(25 \mathrm{~mm})$ was larger than that of homografts or bioprostheses routinely used in children, particularly in cases of primary repair of RV-PA discontinuity. Future studies are mandatory to evaluate smallersized conduits exposed to a more important risk of compression in an infant chest.

Calcification. The three main hypotheses raised by calcium deposition on valvular substitutes are mechanical, biochemical, and time exposure.

There is no clear-cut relation between mechanical stress failure and calcification occurrence. In vitro studies reported calcifications on polyurethane valves after fatigue testing in a systemic loop ${ }^{17}$ and roentgenographic analysis indicated that calcifications were specifically associated with the areas of failure. ${ }^{18,19}$ Thus calcifications should be related to the stress failure observed in a high-pressure system. In vivo, polyurethane mitral valves implanted in juvenile sheep and explanted after 20 weeks were found to be free of failure but presented macroscopic calcified nodules on the outflow surface of the valve and large calcific plaquelike deposits on 


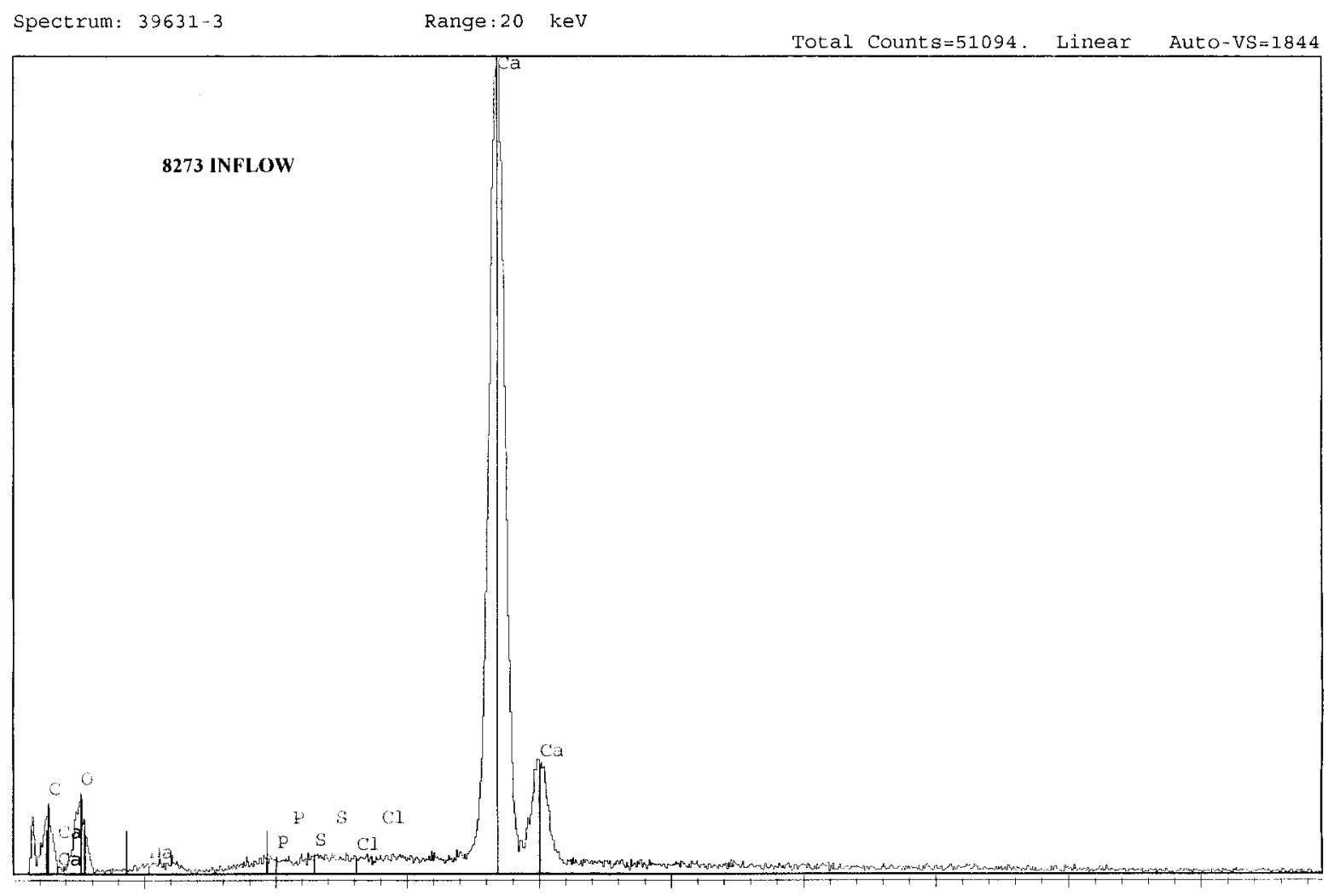

Fig. 4. EDS spectrum of a nodule showing a high calcium content.

the inflow surface. ${ }^{18}$ Similarly, polyurethane valved apicoaortic conduits implanted in calves revealed calcifications without polyurethane failure after 4 to 5 months of follow-up. ${ }^{15}$ In our study, no surface failures were observed on the polyurethane. This may be, in part, because the valves were implanted in a low-pressure cavity.

Calcifications could be related to alterations in the chemical properties of the polyurethane, ${ }^{17}$ because various low molecular weight components extracted from polyurethane are known to form polymer-calcium complexes. ${ }^{17,18}$ Preimplantation exposure to bioactive agents such as antioxidants or surfactants is effective in reducing the calcifications of polyurethane valves. ${ }^{18,20,21}$ However, adsorbed plasma phospholipids and proteins containing carboxylated amino acids may be potential initiators of mineralization of such valves. ${ }^{18}$

The relation between time exposure and calcification occurrence is not clear. In vivo, calcium deposits have been reported on polyurethane valves in the mitral position after 30 days in the sheep ${ }^{18}$ and on artificial heart polyurethane diaphragms after 62 days in the calf. ${ }^{22}$ However, some devices remained free of calcium deposits after 120 days $^{15}$ or 250 days $^{23}$ of observation. In our study the rate of calcification was low within a midterm follow-up (1 year) although the sheep can be considered as an accelerated model of mineralization. ${ }^{18,20}$

Hemodynamic performance. In vivo, early stenosis was reported after polyurethane mitral valve implantations in sheep. ${ }^{18}$ The mean pressure gradients increased from $9.0 \pm 2.2 \mathrm{~mm} \mathrm{Hg}$ at the time of implantation to $17.9 \pm 5.0 \mathrm{~mm} \mathrm{Hg}$ at the end of the study (20 weeks later), but the cardiac output decreased significantly during the same period. In our study, the gradient remained stable over a longer follow-up period without a significant difference in cardiac output. The importance of the gradient could be related to the thickness of the polyurethane ${ }^{24}$; the compound used in our study was 0.3 $\mathrm{mm}$ thick compared with a $0.28 \mathrm{~mm}$ thickness used in the mitral position in another study. ${ }^{18}$

The closing regurgitation (reverse flow during valve closure) and leakage (reverse flow through the closed valve) within the trileaflet polyurethane 
valves is less important than that in most mechanical or biologic valves. ${ }^{24}$ In our study, in the absence of an elevated peak systolic RV-PA gradient, low end-diastolic RV pressure suggested a minimal valvular regurgitation. To improve the evaluation of pulmonary insufficiency, a transthoracic Doppler echocardiographic study was simultaneously performed. However, in the sheep model, the thorax anatomy does not provide a valid RV echographic window, particularly in the postoperative period, because of pleural adhesions that are in the way of ultrasonic waves. Moreover, transesophageal echocardiography was not available. The significant drop observed in RV end-diastolic pressure would suggest a concordant improvement in $\mathrm{RV}$ function which, in the absence of hypovolemia, anemia, or any related state could not be further assessed in this specific experimental setting.

Finally, to address the question of durability, polyurethane valves tested in vitro have demonstrated a lifetime in excess of 130 millions cycles in real time and 420 million cycles under accelerated conditions without polyurethane failure. ${ }^{15}$ In vivo, the longest implant of a similar substitute within an artificial heart was 399 days and was terminated electively because of excessive animal growth. ${ }^{15}$

In summary, these data demonstrate the good hemodynamic performance of polyurethane valved conduits implanted in the right side of the heart and particularly the absence of a significant pressure gradient after 1 year of implantation. This study confirms the good biocompatibility of polyurethane (low thrombogenicity in animals without anticoagulant therapy) and the short-term durability of such composite conduits in an accelerated model of mineralization.

\section{REFERENCES}

1. Keith JD, Rowe RD, Vlad P. Heart disease in infancy and childhood. New York: Macmillan; 1978.

2. Ross DN, Sommerville J. Correction of pulmonary atresia with a homograft aortic valve. Lancet 1966;2:1446-7.

3. Bowman FO, Hancock WD, Malm JR. A valve-containing Dacron prosthesis: its use in restoring pulmonary artery-right ventricular continuity. Arch Surg 1973;107:724-8.

4. Danielson GK, Anderson BJ, Schleck CD, Ilstrup DM. Late results of pulmonary ventricle to pulmonary artery conduits. Semin Thorac Cardiovasc Surg 1995;17:162-7.

5. Jonas RA, Freed MD, Mayer JE, Castaneda AR. Long-term follow-up of patients with synthetic right heart conduits. Circulation 1985;72(suppl):II77-83.

6. Razzouk AJ, Williams W, Cleveland DC, et al. Surgical connections from ventricle to pulmonary artery: comparison of four types of valved implants. Circulation 1992;86(suppl): II154-8.

7. Cartmill TB, Celermajer JM, Stuckey DS, Bowdler JD,
Johnson DC, Hawker RE. Use of the Björk-Shiley tilting disc prothesis in valved conduits for right ventricular outflow reconstruction. Br Heart J 1974;36:1106.

8. Kirklin JW, Blackstone EH, Maehara T, Pacifico AD, Pollock S, Stewart RW. Intermediate-term fate of cryopreserved allograft and xenograft valved conduits. Ann Thorac Surg 1987;44:598-606.

9. Hawkins JA, Bailey WW, Dillon T, Schwartz DC. Midterm results with cryopreserved allograft valved conduits from the right ventricle to the pulmonary arteries. J Thorac Cardiovasc Surg 1992;104:910-6.

10. Sano S, Karl TR, Mee RB. Extracardiac valved conduits in the pulmonary circuit. Ann Thorac Surg 1991;52:285-90.

11. Cleveland DC, Williams W, Razzouk AJ, et al. Failure of cryopreserved homograft valved conduits in the pulmonary circulation. Circulation 1992;86(suppl):II150-3.

12. Boyce SW, Turley K, Yee ES, Verrier ED, Ebert PA. The fate of the $12 \mathrm{~mm}$ porcine valved conduit from the right ventricle to the pulmonary artery: a ten-year experience. J Thorac Cardiovasc Surg 1988;95:201-7.

13. McGoon DC, Danielson GK, Puga FJ, Ritter DG, Mair DD, Ilstrup DM. Late results after extracardiac conduit repair for congenital cardiac defects. Am J Cardiol 1982;49:1741-9.

14. Champsaur G, Ninet J, Vigneron M, Neidecker J, Boissonat P. Use of the ABIOMED BVS System 5000 as a bridge to cardiac transplantation. J Thorac Cardiovasc Surg 1990;100: 122-8.

15. Lederman DM. Technical considerations in the development of clinical systems for temporary and permanent cardiac support. In: Unger F, editor. Assisted circulation 2. Berlin: Springer Verlag; 1984. p. 115-27.

16. Yu LS, Finnegan M, Vaughan S, et al. A compact and noise free electrohydraulic total artificial heart. ASAIO J 1993;39: M386-91.

17. Bernacca GM, Mackay TG, Wilkinson R, Wheatley DJ. Calcification and fatigue failure in a polyurethane heart valve. Biomaterials 1995;16:279-85.

18. Hilbert SL, Ferrans VJ, Tomita Y, Eidbo EE, Jones M. Evaluation of explanted polyurethane trileaflet cardiac valve prosthesis. J Thorac Cardiovasc Surg 1987;94:419-29.

19. Wisman CB, Pierce WS, Donachy JH, Pae WE, Myers JL, Prophet GA. A polyurethane trileaflet cardiac valve prosthesis: in vitro and in vivo stadis. Trans Am Soc Artif Intern Organs 1982;28:164-8.

20. Jones M, Eidbo EE, Walters SM, Ferrans VJ, Clark RE. Effects of two types of preimplantation processes on calcification of bioprosthetic valves. In: Bodnar E, Yacoub M, editors. Biologic and bioprosthetic valves. New York: Yorke Medical Books; 1986. p. 451-9.

21. Arbustini E, Jones M, Moses RD, Eidbo EE, Carroll RJ, Ferrans VJ. Modification by the Hancock T6 process of calcification of bioprosthetic cardiac valves implanted in sheep. Am J Cardiol 1984;53:1388-96.

22. Kolff WJ, Yu LS. The return of elastomer valves. Ann Thorac Surg 1989;48:S98-9.

23. Lo HB, Herold M, Reul H, Muckter H, Taguchi H. A tricuspid polyurethane heart valve as an alternative to mechanical prosthesis or bioprosthesis. Trans Am Soc Artif Intern Organs 1988;34:839-44.

24. Leat ME, Fisher J. Comparative study of the function of the Abiomed polyurethane heart valve for use in left ventricular assist devices. J Biomed Eng 1993;15:516-20. 